\title{
Detection of ventilator associated pneumonia, using clinical pulmonary infection score (CPIS) in critically ill neurological patients
}

\author{
Yogesh Harde', S Manimala Rao 2*, Jyotinarayan Sahoo', Aanchal Bharuka ${ }^{3}$, Betham Swetha and Pulla Saritha ${ }^{4}$ \\ *Correspondence: manimalarao@hotmail.com \\ 'Consultant Critical Care medicine, Yashoda Hospital, Hyderabad, India. \\ ${ }^{2}$ Head, Department of Critical Care Medicine, Yashoda Hospital, Hyderabad, India. \\ ${ }^{3}$ Resident in Anaesthesiology, Diploma National Board, Yashoda hospital, Hyderabad, India. \\ ${ }^{4}$ Consultant respiratory therapy, Yashoda Hospital, Hyderabad, India.
}

\begin{abstract}
Background: Ventilator associated pneumonia (VAP) remains the most common nosocomial infection in the ICU with a very high morbidity, mortality and cost of treatment. Clinical pulmonary infection score (CPIS) can be used prospectively to diagnosis VAP, so as to initiate early treatment and prevent mortality. Most studies indicate that the CPIS has limited value to diagnose VAP. We conducted a prospective study to detect VAP using CPIS score in neurological patients.

Materials and Method: After approval of Ethics Committee, 118 consecutive neurological patients who required ventilatory support for more than 48 hours were studied. CPIS score was calculated every day and when the CPIS score was $\geq 6$, mini-BAL was taken by catheter in catheter technique and was analyzed for microorganism.

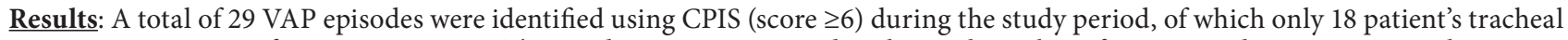
aspirate were positive for microorganism. The incidence rate expressed as the total number of VAP episodes per 1000 ventilation days using CPIS score and tracheal aspirate culture was 36.7(29/789) and 22.87(18/789) respectively in this cohort, but overall our ICU VAP rate in neurological patients using CPIS score and tracheal aspirate culture was 15.19(29/1909) and 9.42(18/1909) respectively. Four patients were found to have early VAP ( $\leq 5$ days of MV) and rest had late VAP. The most common organism was Acinetobactor Baumanni, followed by Enterobacteracae. Early VAP was caused by Enterobacteracae and Acinetobactor causing late VAP.

Conclusion: CPIS score can be a fairly good method to diagnose VAP in critically ill neurological patients, when used reasonably and at the same time can help to restrict unnecessary antibiotic use.
\end{abstract}

Keywords: Ventilator associated pneumonia, clinical pulmonary infection score and neurological patients

\section{Introduction}

VAP is the second most common nosocomial infection and complicates the course in 9 to $27 \%$ of mechanically ventilated patients. VAP contributes to prolonged hospitalization, increase cost and mortality in the range of 24 to $50 \%[1,2]$. In this era when we are struggling to prevent antibiotic resistance, these resistant organisms continue to overpower the critically ill patients and become the major contributors for VAP and mortality $[3,4]$. Patients in the ICU are at risk of dying from critical illness and secondary infection like nosocomial pneumonia $[5,6]$.

Looking at this alarming number, many studies have come up with the aim of early diagnosis of VAP. One of the major score evaluated is Clinical Pulmonary Infection Score (CPIS). But the sensitivity and specificity of this score has always been questioned. A diagnosis of ventilator-associated pneumonia is suspected when the patient has a new infiltrate on chest $\mathrm{x}$-ray along with fever and raised leucocyte count after 48 hours of invasive mechanical ventilation [1].

To diagnose a VAP episode, the presence of clinical signs of pneumonia plus microbiologic confirmation by quantitative cultures is required. It can be obtained from either tracheal aspirate, Bronchoalveolar Lavage (BAL), Mini-BAL or Protected Brush Specimens (PBS), each having sensitivity and specificity of $38-100 \%$ and $14-100 \%, 42-93 \%$ and $45-100 \%, 63-100 \%$ and $66-96 \%, 33-100 \%$ and $50-100 \%$ respectively [7].

Taking this into account, we conducted a study to assess whether CPIS score can stand as a dependable tool for early detection of VAP in subset of neurologically ill patients.

\section{Material and Method}

This prospective study was conducted between January 2011 to October 2011 in the 20 bedded medical-surgical ICU in a tertiary care medical centre in south India. During the study period, a total of 1349 patients were admitted to the ICU, out of which 475 patient's required mechanical ventilation. One hundred eighteen patients were included in our study, who required mechanical ventilated for neurological indication.

\section{Inclusion criteria}

-Patients who had received mechanical ventilation for $>48$ hour 
Harde et al. Journal of Anesthesiology and Clinical Science 2013,

http://www.hoajonline.com/journals/pdf/2049-9752-2-20.pdf

doi: $10.7243 / 2049-9752-2-20$

Table 1. Demographic data.

\begin{tabular}{lccc}
\hline Sex & VAP(18) & NO VAP(84) & P -value \\
\hline Male & 15 & 67 & 0.732 \\
Female & 3 & 17 & - \\
DM & 5 & 28 & 0.651 \\
HTN & 8 & 38 & 0.952 \\
CAD & 0 & 8 & 0.149 \\
TRACHEOSTOMY & 11 & 16 & 0.000 \\
ICU Stay & $17.39(8.833)$ & $9.12(5.043)$ & 0.000 \\
MV Days & $13.28(7.880)$ & $6.55(4.336)$ & 0.000 \\
APACHE-II & $14.83(3.666)$ & $14.21(3.716)$ & 0.522 \\
AGE & $50.00(19.17)$ & $51.67(18.96)$ & 0.736 \\
MORTALITY & $8 / 18$ & $26 / 84$ & 0.96 \\
\hline \multicolumn{5}{r}{}
\end{tabular}

Table 2. Organism.

\begin{tabular}{lc}
\hline No Organism & 11 \\
\hline Acinetobactor & 9 \\
Pseudomonas & 2 \\
Enterobactor & 4 \\
Klebsiella & 3 \\
\hline
\end{tabular}

for neurological cause.

-Patient's age $>18$ years.

\section{Exclusion criteria}

-Patients receiving mechanical ventilation for pulmonary indication.

-Patients on cancer chemotherapy and immunosuppressive drugs.

-Patient with chronic lung disease, chronic hepatic disease, chronic cardiac disease and chronic kidney disease.

- Patients with AIDS, cancer and neutropenia.

-Patients intubated and mechanical ventilated outside the ICU before admission.

\section{Study protocol}

The following protocol was performed in the same sequence in all study patients.

-Thorough blind endotracheal suction was done using a sterile $12 \mathrm{~F}$ catheter.

-Chest vibration or percussion for $10 \mathrm{~min}$.

-Pre oxygenation with $\mathrm{FiO}_{2}$ of $30 \%$ above the patient requirement.

-Blind endotracheal aspiration was performed with sterile catheter-in-catheter technique using a 20F outer suction catheter and $10 \mathrm{~F}$ inner suction catheter with a mucus trap. The outer catheter was introduced $2 \mathrm{~cm}$ beyond the ET tube tip and the inner catheter was passed through the outer catheter till resistance felt (carina), then the inner catheter is withdrawn $1 \mathrm{~cm}$, followed by tracheal secretions aspiration through the inner catheter.

- Minimum of $2 \mathrm{ml}$ of endotracheal aspirate is collected.

- All samples were processed in the microbiology laboratory within 20 minutes of collection.

- Bacterial identification and antibiotic susceptibility tests using standard methods were performed only for microorganisms that were present at a concentration $>10^{5} \mathrm{cfu} / \mathrm{mL}$.

\section{Data collection}

The following information was recorded prospectively: On ICU admission: age, sex, cause of ICU admission, location prior to ICU admission, co morbidities, diagnosis, ABG, chest roentgenogram, APACHE-II score and sequential organ failure assessment (SOFA).

At the time of intubation and mechanical ventilation: modified CPIS parameter, ABG, SOFA score and APACHE-II score After intubation and mechanical ventilation: ABG modified CPIS parameter, days of $\mathrm{MV}$, length of stay in the ICU and outcome.

All parameter were calculated and collected by one of the investigators, independent of the treating physicians in charge.

\section{Results}

During the study period of 10 months, 1349 patients were admitted in the ICU and 118 patients (8.74\%) were enrolled in the study. CPIS score and tracheal samples of 16 patients could not be optimally processed in the laboratory and only 102 patients' data were analysed. These 102 patients were mechanically ventilated for a total of 789 days due to neurological cause, after inclusion in our study.

67 patients (66.7\%) survived while 34 (33.3\%) died during their stay in ICU. During sample collection period of 13 days, 6 patients died on day 6,1 on day 8 and 2 on day 9 . The remaining 25 patients out of 34 non-survivors died during the 28 days of ICU stay.

Table 1 lists the demographic profile of study patients. Patients did not differ significantly between the VAP and non VAP cohort with respect to age, sex, main reason for ICU admission and co- morbidities. The mean duration of ICU stay was 17.39 days (SD-8.833) in VAP patients, which were significant ( $p-0.00$ ) compared to non VAP patients ( 9.12 days, SD-5.043). Mean duration of MV was 13.28 days ( $S D=7.880)$ in VAP patients, which was significant $(p-0.00)$ than non VAP group 6.55 days $(S D=4.336)$.

A total of 29VAP episodes were identified using CPIS (score $\geq 6$ ) during the study period. From these 29 VAP episodes diagnosed by CPIS score of $\geq 6$, only 18 patient's tracheal aspirate were positive for microorganism. The incidence rate expressed as the total number of VAP episodes per 1000 ventilation days using CPIS score and tracheal aspirate culture was 36.7(29/789) and 22.87(18/789) respectively in this cohort, but overall ICU VAP rate in neurological patients using CPIS score and tracheal aspirate culture was 15.19(29/1909) and 9.42(18/1909) respectively. Four patients were found to have early VAP ( $\leq 5$ days of MV) and rest had late VAP.

Microorganism associated with VAP episode is reported in Table 2. The most common organism was Acinetobactor Baumanni, followed by Enterobacteracae. Early VAP were caused by Enterobacteracae (3/4) and Acinetobactor causing late VAP (8/14). 
Harde et al. Journal of Anesthesiology and Clinical Science 2013, http://www.hoajonline.com/journals/pdf/2049-9752-2-20.pdf

Table 3. The modified clinical pulmonary infection score.

\begin{tabular}{lccc}
\hline CPIS Points & 0 & 1 & 2 \\
\hline Tracheal secretions & Rare & Abundant & Abundant + purulent \\
Chest X-ray infiltrates & No infiltrate & Diffused & Localized \\
Temperature, ${ }^{\circ} \mathbf{C}$ & 36.5 and 38.4 & 38.5 and & 39 or 36 \\
& & 38.9 & \\
Leukocytes count, per $\mathbf{~ m m 3}$ & 4,000 and 11,000 & $<4,000$ or $>$ & $<4,000$ or $>11,000+$ \\
& & 11,000 & band forms 500 \\
PAO2/FIO2, $\mathbf{m m ~ H g}$ & $>240$ or ARDS & - & 240 and no evidence \\
& & & of ARDS \\
microbiology & negative & - & positive \\
\hline
\end{tabular}

Agreement between CPIS and P/F ratio was observed throughout the study period. Correlation between CPIS with WBC count and chest radiography was observed during the first 7 days and with no correlation later on.

In our patient population both the severity scores (SOFA/ APACHE II) and co morbidities did not have any discriminating power to differentiate VAP from non-VAP. Patients with VAP had longer ICU stay, MV days and required tracheostomy.

\section{Discussion}

HAP accounts for up to $25 \%$ of all ICU infection and for more than $50 \%$ of the antibiotic prescribed [1]. VAP occurs in $9-27 \%$ of all intubated patients. In ICU nearly $90 \%$ of episodes of HAP occur in intubated patients $[1,2,5]$. Since the original investigation, clinical utility of this diagnostic score has been a matter of interest and numerous investigators have studied the usefulness of the CPIS as a diagnostic tool, with limited success $[\mathbf{1}, \mathbf{8}, 9]$. No studies have specifically addressed the CPIS in critically ill patients with neurological etiology, despite the high occurrence of microaspiration in such patient population. The fundamental obstacle to the diagnosis of VAP is the absence of a uniform gold standard [8].

Intensivist suspecting VAP has no single test, assay or intervention that they can rely upon to diagnose or exclude VAP $[8,10]$. Instead, the intensivist and the infection control practitioners integrate multiple nonspecific signs such as fever, increased pulmonary secretions, leukocyte count, radiographic opacities and tracheal secretion culture result to diagnose VAP $[11,1]$. These clinical signs however are nonspecific and can be seen in a host of conditions like pulmonary edema, sepsis, Acute Respiratory Distress Syndrome, pulmonary embolism and atelectasis $[\mathbf{1 2}, \mathbf{1 3}]$.

Several studies had used tracheal aspirate surveillance to detect microorganism causing VAP. By using tracheal aspirate surveillance culture more patients are diagnosed to have VAP and receive antibiotic $[4,14,15,16]$. This therapy could lead to antibiotic over use and the development of multi drug resistant organisms $[4,17]$.

The important findings of our study include the following:

1. Twenty nine VAP episodes were diagnosed by using CPIS $(\geq 6), 18$ of the 29 mini BAL samples were positive for microorganism.
2. The incidence rate of VAP per 1000 ventilator day is 36.7 and 22.87 using CPIS and mini BAL fluid culture respectively.

3. Agreement between CPIS and $\mathrm{P}_{\mathrm{a}} \mathrm{O}_{2} / \mathrm{FiO}_{2}$ was observed throughout the study period, whereas agreement between CPIS with leucocyte count and chest X-ray was observed during the first 7 days of mechanical ventilation.

4. The majority of early VAP was caused by Enterobacteracae and late VAP by Acinetobactor Baumanni.

Outcome of patients with VAP largely depends on early and appropriate empirical antibiotic therapy followed by deescalation when specific microbiological data become available after 72 hours $[2,3,17]$. Results of our study indicate that CPIS can be a reliable tool to diagnose VAP and start empirical antibiotic early in patients intubated and mechanically ventilated (MV) for non-pulmonary cause. In MV patients the incidence of VAP increases with duration of ventilation and the risk is higher early in the course of ventilation [18].

Intubation and mechanical ventilation increase the risk of HAP by 6 to 20 fold [1]. HAP in mechanically ventilated patient initially has ventilator associated tracheobronchitis (VAT) subsequently infection moves down to involve the lung parenchyma causing VAP which is caused by similar microbiological agent causing tracheobronchitis. VAP involve diffusely, bilaterally and predominantly in the dependent lung segment, making blind BAL as accurate as bronchoscopic sampling for diagnosis of VAP $[19,3,20]$.

Pugin et al., introduced CPIS and found that threshold score of $\geq 6$ was a fairly accurate indicator of VAP [9]. CPIS have been modified by excluding tracheal aspirate specimen culture (modified CPIS Table 3 ) and increasing the score to $7[\mathbf{8}, \mathbf{2 1}, \mathbf{2 2}, \mathbf{1 3}, \mathbf{2 3}]$. Various studies have reported CPIS to have sensitivity and specificity between $77 \%$ to $93 \%$ and $17 \%$ to $100 \%$ respectively $[\mathbf{1 8 , 2 1}]$. Fabregas et al., found that CPIS with BAL fluid $>10^{4} \mathrm{cfu} / \mathrm{mL}$ had a sensitivity of $77 \%$ and specificity of $58 \%$ when compared with post mortem lung biopsy histology $[\mathbf{2 4}, \mathbf{2 5}]$. Similar to other studies in which culture of lower respiratory tract specimen of patients with VAP showed $60 \%$ (50\%-80\%) positive for microorganism [8,9]. In our study 29 VAP episodes were diagnosed using CPIS $\geq 6$, out of which only 18 (66.7\%) were positive for microorganism. In our study the high incidence of VAP (using CPIS score-36.7 and microbiological criteria-22.87) in neurological patients could be attributed to poor neurological condition and small sample size.

There is significant $(p-0.005)$ correlation between the CPIS score with $\mathrm{P}_{\mathrm{a}} \mathrm{O}_{2} / \mathrm{FiO}_{2}, \mathrm{TLC}$ and chest $\mathrm{X}$-ray in the first seven days of intubation and MV. The parameter that significantly correlated after 7 days of $\mathrm{MV}$ was $\mathrm{P}_{\mathrm{a}} \mathrm{O}_{2} / \mathrm{FiO}_{2}$ and poor correlation of TLC and chest X-ray after 7 days of MV could be due to confounding factors like presence of atelectasis, multiple invasive lines, prolonged immobilization and colonization or subclinical infection during prolonged ICU stay $[\mathbf{1 1}, \mathbf{1}]$.

In our study there was non-significant difference in mortality 
between VAP and non VAP as most died of neurological failure rather than due to VAP. Of the eight deaths in VAP group only 2 died of ARDS with hypoxemia and septic shock. This mortality rate is in accordance with other studies in which 33\% to $50 \%$ death is attributed to VAP $[3,5,6]$. High mortality rate in patients with VAP is usually due to delayed and inappropriate treatment, bacteraemia with virulent organism, and presence of underlying medical condition [6].

\section{Conclusion}

CPIS is a reasonable tool to detect early VAP in critically ill neurological patients when used appropriately and can prevent antibiotic over use. Among the parameters of CPIS, low $\mathrm{PaO}_{2} / \mathrm{FiO}_{2}$ ratio correlates well with VAP episodes and found to be a good indicator. Early detection and appropriate broad spectrum empiric therapy with de-escalation when cultures are available can reduce the morbidity, mortality and antibiotic overuse.

\section{Competing interests}

The Authors declare that they have no competing interests.

\section{Publication history}

Received: 25-Jan-2013 Revised: 25-Feb-2013

Accepted: 28-Feb-2013 Published: 18-Mar-2013

\section{References}

1. Niederman MS, Craven DE, Bonten MJ: American Thoracic Society and Infectious Diseases society of America (ATS/IDSA). Guideline for the management of adults with hospital-acquired, ventilator-associated, and healthcare-associated pneumonia. Am J Respir Crit Care Med 2005; 171: 388-416. | Article

2. Chastre $J$ and Fagon JY: Ventilator-associated pneumonia. Am J Respir Crit Care Med 2002, 165:867-903. | Article | PubMed

3. Craven DE, Chroneou A, Zias N and Hjalmarson KI: Ventilator-associated tracheobronchitis: the impact of targeted antibiotic therapy on patient outcomes. Chest 2009, 135:521-8. | Article | PubMed

4. Michel F, Franceschini B, Berger P, Arnal JM, Gainnier M, Sainty JM and Papazian L: Early antibiotic treatment for BAL-confirmed ventilatorassociated pneumonia: a role for routine endotracheal aspirate cultures. Chest 2005, 127:589-97. | Article | PubMed

5. Richards MJ, Edwards JR, Culver DH and Gaynes RP: Nosocomial infections in medical intensive care units in the United States. National Nosocomial Infections Surveillance System. Crit Care Med 1999, 27:88792. | Article | PubMed

6. Heyland DK, Cook DJ, Griffith L, Keenan SP and Brun-Buisson C: The attributable morbidity and mortality of ventilator-associated pneumonia in the critically ill patient. The Canadian Critical Trials Group. Am J Respir Crit Care Med 1999, 159:1249-56. | Article | PubMed

7. Grossman RF and Fein A: Evidence-based assessment of diagnostic tests for ventilator-associated pneumonia. Executive summary. Chest 2000, 117:177S-181S. | PubMed

8. Zilberberg MD and Shorr AF: Ventilator-associated pneumonia: the clinical pulmonary infection score as a surrogate for diagnostics and outcome. Clin Infect Dis 2010, 51 Suppl 1:S131-5. | Article | PubMed

9. Pugin J, Auckenthaler R, Mili N, Janssens JP, Lew PD and Suter PM: Diagnosis of ventilator-associated pneumonia by bacteriologic analysis of bronchoscopic and nonbronchoscopic "blind" bronchoalveolar lavage fluid. Am Rev Respir Dis 1991, 143:1121-9. | Article | PubMed

10. Pham LH, Brun-Buisson C, Legrand P, Rauss A, Verra F, Brochard L and Lemaire F: Diagnosis of nosocomial pneumonia in mechanically ventilated patients. Comparison of a plugged telescoping catheter with the protected specimen brush. Am Rev Respir Dis 1991, 143:1055-61. | Article I PubMed

11. Klompas M: Does this patient have ventilator-associated pneumonia?
JAMA 2007, 297:1583-93. | Article | PubMed

12. Klompas M, Kulldorff M and Platt R: Risk of misleading ventilatorassociated pneumonia rates with use of standard clinical and microbiological criteria. Clin Infect Dis 2008, 46:1443-6. | Article | PubMed

13. Napolitano LM: Use of severity scoring and stratification factors in clinical trials of hospital-acquired and ventilator-associated pneumonia. Clin Infect Dis 2010, 51 Suppl 1:S67-80. | Article | PubMed

14. Jourdain B, Novara A, Joly-Guillou ML, Dombret MC, Calvat S, Trouillet $\mathrm{JL}$, Gibert $\mathrm{C}$ and Chastre J: Role of quantitative cultures of endotracheal aspirates in the diagnosis of nosocomial pneumonia. Am J Respir Crit Care Med 1995, 152:241-6. | Article | PubMed

15. Fagon JY, Chastre J, Wolff M, Gervais C, Parer-Aubas S, Stephan F, Similowski T, Mercat A, Diehl JL, Sollet JP and Tenaillon A: Invasive and noninvasive strategies for management of suspected ventilatorassociated pneumonia. A randomized trial. Ann Intern Med 2000, 132:621-30. | Article | PubMed

16. Baker AM, Bowton DL and Haponik EF: Decision making in nosocomial pneumonia. An analytic approach to the interpretation of quantitative bronchoscopic cultures. Chest 1995, 107:85-95. | Article | PubMed

17. Iregui M, Ward S, Sherman G, Fraser VJ and Kollef MH: Clinical importance of delays in the initiation of appropriate antibiotic treatment for ventilator-associated pneumonia. Chest 2002, 122:262-8. | Article | PubMed

18. Cook DJ, Walter SD, Cook RJ, Griffith LE, Guyatt GH, Leasa D, Jaeschke $\mathrm{RZ}$ and Brun-Buisson C: Incidence of and risk factors for ventilatorassociated pneumonia in critically ill patients. Ann Intern Med 1998, 129:433-40. | Article | PubMed

19. Nseir S, Di Pompeo C, Pronnier P, Beague S, Onimus T, Saulnier F, Grandbastien B, Mathieu D, Delvallez-Roussel M and Durocher A: Nosocomial tracheobronchitis in mechanically ventilated patients: incidence, aetiology and outcome. Eur Respir J 2002, 20:1483-9. | Article | PubMed

20. Craven DE and Hjalmarson KI: Ventilator-associated tracheobronchitis and pneumonia: thinking outside the box. Clin Infect Dis 2010, 51 Suppl 1:S59-66. | Article | PubMed

21. Fartoukh M, Maitre B, Honore S, Cerf C, Zahar JR and Brun-Buisson C: Diagnosing pneumonia during mechanical ventilation: the clinical pulmonary infection score revisited. Am J Respir Crit Care Med 2003, 168:173-9. | Article | PubMed

22. Kirtland SH, Corley DE, Winterbauer RH, Springmeyer SC, Casey KR, Hampson NB and Dreis DF: The diagnosis of ventilator-associated pneumonia: a comparison of histologic, microbiologic, and clinical criteria. Chest 1997, 112:445-57. | Article | PubMed

23. Singh N, Rogers P, Atwood CW, Wagener MM and Yu VL: Short-course empiric antibiotic therapy for patients with pulmonary infiltrates in the intensive care unit. A proposed solution for indiscriminate antibiotic prescription. Am J Respir Crit Care Med 2000, 162:505-11. | Article | PubMed

24. Fabregas N, Ewig S, Torres A, El-Ebiary M, Ramirez J, de La Bellacasa $\mathrm{JP}$, Bauer T and Cabello $\mathrm{H}$ : Clinical diagnosis of ventilator associated pneumonia revisited: comparative validation using immediate postmortem lung biopsies. Thorax 1999, 54:867-73. | Article | PubMed Abstract | PubMed Full Text

25. NI Stewart and BH Cuthbertson: The problems diagnosing ventilator associated Pneumonia. The Intensive Care Society 2009, 10:4JICS. | PDF

Citation:

Harde Y, Rao S M, Sahoo J N, Bharuka A, Betham $S$ and Pulla S: Detection of ventilator associated pneumonia, using clinical pulmonary infection score (CPIS) in critically ill neurological patients. journal of Anesthesiology and Clinical Science 2013, 2:20. http://dx.doi.org/10.7243/2049-9752-2-20 